Dr. Siemens has, in his paper, further suggested that solar radiation may effect the dissociation in interstellar space of the compounds of oxygen with carbon and with hydrogen, so that these elements may reach the sun in an uncombined state, ard there be burned. He would thus make the sun not orly a compressing-engine, but a furnace. While such a dissociation in outer space is not impossible, it is to be said that a preliminary decomposition, followed by reunion in the solar sphere, would in no way augment the ultimate calorific effect of compression there. The elements in the act of dissociation in space would absorb just as much radiant energy as would be set free by their subsequent combination, so that, whether the solar radiations are expended in heating or in dissociating the diffused matter, the final result in the sun would be the same. It may be further remarked, that from what we know of solar chemistry, dis: ociation of aqueous vapour and of carbonic dioxide is more likely to take place in the sun itself than in the cold regions of outer space.

While, therefore, his suggested addition to the hypothesis seems, if not untenable, unnecessary, we are grateful to Dr. Siersens for again bringing before us the grand conception which dawned upon the mind of Newton, but has found its fuller expression in our own day, and, as I have endeavoured to show in the papers already noticed, gives us the elements of a rational Physiology of the Univer: e.

Montreal, Canada, April 3

T. Sterry Hunt

THE two preceding letters by American men of science of wellknown position, grant one of the three postulates upon which I grounded my solar plan, that of space filled with attenuated matter; they do not object to the second, and all-important one of the equatorial outflowing current; tut they call in question the necessity of the third, that of dissociation of attenuated matter in space by means of arrested solar energy. Both my critics think dissociation in space unnecessary for the maintenance of solar energy, or as Dr. Sterry Hunt very clearly puts it : "Whether the solar radiations are expended in heating or in dissociating the diffused matter, the final result in the sun would ke the same."

I would be disposed to agree with this dictum if taken as an abstract proposition, but I do not think that my critics can have subjected their view to calculation, the keystone without which the arch of speculation cannot $\mathrm{ke}$ considered as secure. We know by experimental evidence that stellar space, and the matter filling it, are intensely cold, as proved by the winter-temperature of the folar regions; moreover water exposed even in the tropics to free radiation while insulated from the warm earth, freezes to a considerable thickness during a single night.

Let us suppose that the attenuated matter in space has a temperature of $160^{\circ}$ on the absolute scale (being $114^{\circ}$ below the freezing-point of water), and that it is 3000 times more rarefied than when it $r \in$ aches by adiabatic comparison the solar photosphere. The rise of temperature due to this compression must be according to Rankine's well-known formula-

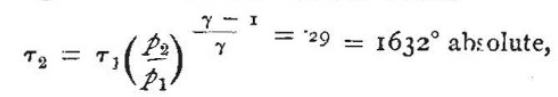

and this would make the solar photosphere $135^{\circ}$ on the Centigrade scale; this temperature is quite inadequate to produce the solar luminosity, which must require one equalling, though probably not exceeding that of the electric arc.

But assuming a compression of the attenuated atmosphere up to the photospheric density (which according to most authoritie does not exceed terrestrial atmospheric density), there would still remain the predicament that although a higher maximum tem. Ferature could be reached by compression, very little of the heat due to it could be spared for the purpose of radiation, without sacrificing the possibility of disposing of the refrigerated gases again into space. The refrigerated gases would obey the law of solar gravitation to a much greater extent than the heated incoming gases, and would certainly not pass away into space, unless acted upon ty a considerable extraneous force. The mere passage of the solar orb throngh space at a majestic pace which does not exceed one quarter of our orbital velocity, could not possibly produce such a result, and ever, the fan action advocated in my paper wonld fail to work in opposition to a large determining influencc of solar gravitation.

These conditions are entirely changed if we assume, in addition to adiabatic compression and re-expansion, a further source of heat such as is produced in comtustion. Ore pound of hydrogen deve'ops in burning about 60,000 heat units, and one pound of marsh gas 24, cco heat units; in my article upon this subject, published in the April numter of the Ninetenth Century, I showed that if only one-twentieth portion of the gases streaming in upon the polar : urfaces at the face of Ico feet a secord were combustible gases, they could produce an amount of heat more than sufficient to account for the entire solar radiation as determined by Herschel and Pcuillet.

There is no reason for supposing that the instreaming gases would penetrate beyond the solar ,hotosphere; they would fla: $h$ into combustion whenever their temperature by adiabatic compres:ion had reached the limit of spontaneous ignition without the presence of an igniting solid, a point $u$ hich, if determined experimentally, would give a clue to the real vapour dencity of the photosphere; and after reaching the point of disscciation, combustion would continue in the measure of the abstraction of heat by radiation, thus producing a vast accumulation of igneous matter of comparatively low density. This would flow on, in the manner of a floating body, above the denser gases or vapours forming part of the permanent body of the sun, towards the equatorial regions, whence it wculd te propelled into space at a temperature exceeding to some extent that of the inflowing gases after compression, but before combustion, thus aiding, instead of retarding the supposed solar fan action.

The fan-action itself would be produced, no doubt, at the expense of solar rotation; but, in order to appreciate this re. tarding influence at its true value, it must be borne in mind that the flow of gases once established has only to be changed in direction; the velocity acquired by the ir.flowing gases is simply transferred to the outflowing current diminished by an amount of rotative force sufficient to cover frictional retardation. The very interesting leading article in last week'S NATURE, regarding the solar observations in Ameica, during the last eclipses, now publisbed for the first time, furnishes an unexfected and most striking corroboration of the solar fan-action which I bad ventured to put forward as a necessary' consequence of solar rotation in space filled $w$ ith attenuated matter.

I am well aware that my paper read before the Royal Society does scant justice to those who have devoted much time ard ingenuity to the subject of solar physics, and that, morecver, many points of consicierable interest connected with the views I advocate have been indicated only, instead of having been fully developed; but, on the whole, I thought it was better to present my views in mere outline before an audience well acquainted with our present information regarding solar physics, and with only half an hou's time at their disposal.

The elaboration of such a subject would necessitate the writing of a book rather than of a paper, and perhaps Dr. Sterry Hunt, who has already done so much to elucidate our present knowledge of solar physics, may be induced to extend bis labours in this direction.

12, Queen Anne's Gate, Westminster, April 26

\section{Silurian Fossils in the North-West Highlands}

My friend, Mr. Hudleston, in bis letter on the Silurian fossils in the North-we:tern Highlar.ds, states very clearly a point which at the present time is of the highest importance to all students of the metamorphic rocks. If it can be proved that the Durness limestone, which contains undoubted lower Silurian fossils, is identical with the series in W'e:tern Sutherland and Ross, which Mr. Hudleston terms the quartzo-dolomitic, then the so-called "Newer Gneiss" must be more recent than it, and thus must be a metamorphosed representative of some part of the Silurian series. Tbis would prove that very great regional metamorphism has taken place in the latter half of the Palæozoic period; and that its mineral condition will not aid us materially in determining the age of a rock which has once been stratified.

But is this identity proved; and is it certain that the Durness limestone is more ancient than the Newer Gneiss series? I have not myself had the opportunity of investigating the Durness region, though I bave examined several specimens of its limestone; and from the condition of these and my knowledge of parallel cases, and of metamorpbic rocks in general, do not hesitate to say that I should require very clear stratigraf hical evidence before I could believe the Durners simestone to underlie the "Newer Gneiss." The former is no more metamorphic than are several of the Palrozoic limestones; the latter is always considerably, sometimes rather bighly, metamorphosed. But in 